www.nature.com/ja

\title{
Isolation and characterization of 23-0-mycinosyl-20- dihydro-rosamicin: a new rosamicin analogue derived from engineered Micromonospora rosaria
}

\author{
Yojiro Anzai ${ }^{1}$, Ayami Sakai ${ }^{1}$, Wei Li $^{1}$, Yohei Iizaka ${ }^{1}, K$ Kazuo Koike ${ }^{1}$, Kenji Kinoshita ${ }^{2}$ and Fumio Kato ${ }^{1}$
}

The Journal of Antibiotics (2010) 63, 325-328; doi:10.1038/ja.2010.38; published online 23 April 2010

Keywords: genetic engineering; mycinose; rosamicin

\begin{abstract}
Macrolides, including some of the most important antibiotics clinically used, contain deoxysugars attached to an aglycone core. These sugars often impart specific biological activity to the molecule or enhance this activity. Many genes involved in the biosynthesis of macrolide antibiotics have been cloned and sequenced; in addition, the functions of many proteins encoded by macrolide biosynthetic genes have been elucidated. With this information and experimental results, manipulation of the polyketide synthase and deoxysugar biosynthetic pathways to create novel macrolide antibiotics has become possible. ${ }^{1}$ Therefore, a combined approach that uses genes involved in the biosynthesis of macrolactone rings and deoxysugars, and in the glycosylation of macrolactone rings has been used to modify the macrolide structure. ${ }^{2}$
\end{abstract}

Rosamicin (that is rosaramicin; Figure 1) is a 16 -membered macrolide antibiotic produced by Micromonospora rosaria IFO13697 (that is NRRL 3718). ${ }^{3}$ It contains a branched lactone and deoxyhexose sugar D-desosamine at the C-5 position. The engineered strain M. rosaria TPMA0001 carries genes involved in the D-mycinose biosynthetic pathway of Micromonospora griseorubida A11725, namely, $m y c C I, m y c C I I, m y c D, m y c E, m y c F, m y d H$ and $m y d I$; this engineered strain was found to produce a mycinosyl rosamicin derivative IZI. ${ }^{4}$ M. griseorubida A11725 produces the 16-membered macrolide antibiotic mycinamicin II, which comprises a branched lactone and two different deoxyhexose sugars-D-desosamine and D-mycinose-at the C-5 and C-21 positions, respectively. All the genes involved in D-mycinose biosynthesis lie on the mycinamicin biosynthetic gene cluster. ${ }^{5}$ The functions of these gene products have been elucidated through chemical, genetic and enzymatic analyses. The genes mycCI and mycCII encode a cytochrome P450 enzyme and ferredoxin, respectively, which function in combination with ferredoxin reductase to mediate the hydroxylation of mycinamicin VIII at the C-21 methyl group. On completion of this hydroxylation reaction, $\mathrm{MycD}$ transfers
6-deoxy-D-allose to the C-21 hydroxyl group by using dTDP-6-deoxyD-allose as a substrate; dTDP-6-deoxy-D-allose is synthesized from dTDP-4-keto and 6-deoxy-D-glucose by MydH and MydI. The methyltransferases $\mathrm{MycE}$ and $\mathrm{MycF}$ convert the resulting compound mycinamicin VI to mycinamicin IV, which has D-mycinose attached at the $\mathrm{C}-21$ position. In particular, we have recently elucidated the biochemical functions of $\mathrm{MycCI}, \mathrm{MycCII}, \mathrm{MycE}$ and $\mathrm{MycF}$ by using the purified form of these proteins, which were overexpressed in Escherichia coli. ${ }^{6,7}$ In our earlier study, when EtOAc extracts obtained from culture broths of the wild-strain M. rosaria IFO13697 and the engineered strain $M$. rosaria TPMA0001 were compared using HPLC, two additional peaks-IZI and IZII-appeared in the chromatogram (at $285 \mathrm{~nm}$ ) of the extract from the engineered strain. IZI was identified as a mycinosyl rosamicin derivative, 23-O-mycinosyl-20deoxo-20-dihydro-12,13-deepoxyrosamicin. ${ }^{4}$ Moreover, our detailed studies showed that another metabolite (designated as IZIII) was produced by the engineered strain. Here, we report the isolation and characterization of a novel mycinosyl rosamicin derivative IZIII; that is, 23-O-mycinosyl-20-dihydro-rosamicin (Figure 1), produced by M. rosaria TPMA0001. Moreover, the structure of IZII was also determined as 23-O-mycinosyl-20-dihydro-12,13-deepoxyrosamicin (Figure 1).

$M$. rosaria TPMA0001 and the wild-type strain $M$. rosaria IFO13697 were cultured at $27^{\circ} \mathrm{C}$ in $5 \mathrm{ml}$ of trypticase soy broth (Becton, Dickinson and Company, Sparks, MD, USA) for 8 days. The broth was adjusted to $\mathrm{pH} 9-11$ with $28 \%$ ammonia solution and extracted with an equal volume of EtOAc; the extract was then concentrated in vacuo. The crude extracts were dissolved with EtOAc, and then an equal volume of $0.1 \%$ trifluoroacetic acid (TFA) was added. The water layer containing rosamicins was adjusted to $\mathrm{pH} 9-11$ with $28 \%$ ammonia solution and extracted with an equal volume of EtOAc. The organic layer was concentrated in vacuo, and

${ }^{1}$ Faculty of Pharmaceutical Sciences, Toho University, Funabashi, Chiba, Japan and ${ }^{2}$ School of Pharmaceutical Sciences, Mukogawa Women's University, Koshien, Nishinomiya, Hyogo, Japan

Correspondence: Dr Y Anzai, Department of Microbiology, Faculty of Pharmaceutical Sciences, Toho University, 2-2-1 Miyama, Funabashi, Chiba 274-8510, Japan. E-mail: yanzai@phar.toho-u.ac.jp

Received 7 January 2010; revised 1 April 2010; accepted 2 April 2010; published online 23 April 2010 

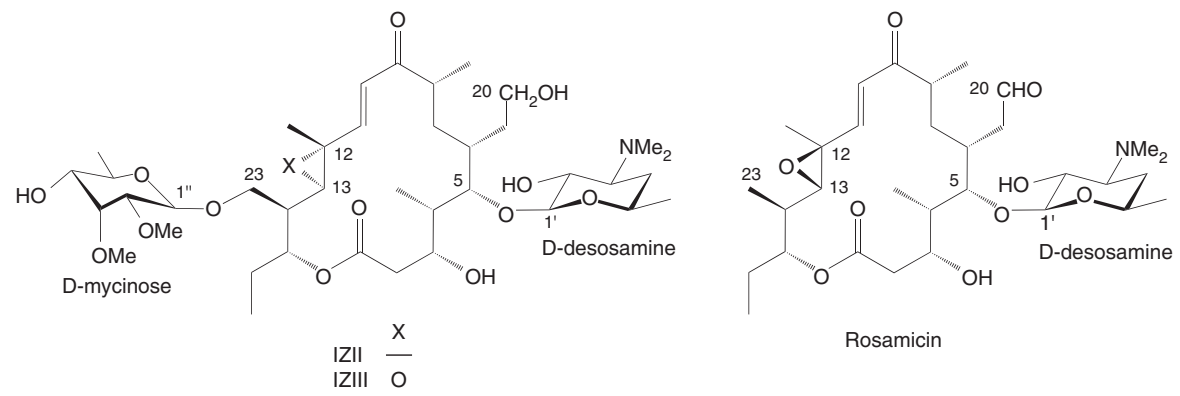

Figure 1 Structures of IZII, IZIII and rosamicin.
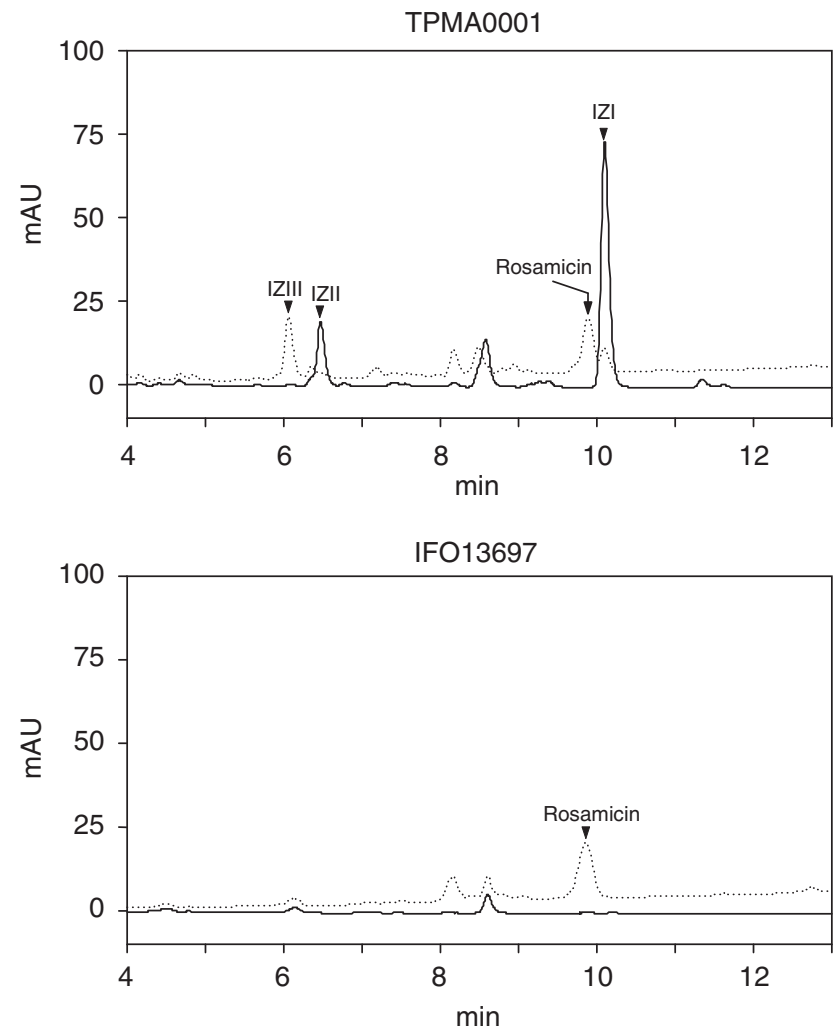

Figure 2 HPLC chromatograms of the EtOAc extract obtained from $M$. rosaria TPMA0001and $M$. rosaria IF013697. Solid line, at $285 \mathrm{~nm}$; dashed line, at $240 \mathrm{~nm}$.

each residue was dissolved in MeOH for HPLC and LC-MS analyses. HPLC analysis scanning with a diode array detector model L-2450 (Hitachi, Tokyo, Japan) was performed on the following condition: ODS-80TM, i.d. $=150 \times 4.6 \mathrm{~mm}$ (Toso, Tokyo, Japan); mobile phase, $25-60 \%$ solvent $\mathrm{B}$ over $15 \mathrm{~min}$ ( $\mathrm{A}=$ deionized water $+0.1 \% \mathrm{TFA}$, $\mathrm{B}=$ acetonitrile $+0.1 \% \mathrm{TFA}$ ); flow rate, $1.0 \mathrm{ml} \mathrm{min}^{-1}$; UV wavelength, 200-300 nm. In HPLC chromatograms recorded at $240 \mathrm{~nm}$, rosamicin was detected at $11.16 \mathrm{~min}$ in the samples from both strains, TPMA0001 and IFO13697 (rosamicin productivity, 0.3 and $0.1 \mathrm{mgl}^{-1}$, respectively), and a new peak of IZIII also appeared at $6.08 \mathrm{~min}$ in the chromatogram of TPMA0001 (Figure 2). Moreover, additional two peaks of IZI and IZII appeared at 10.11 and $6.49 \mathrm{~min}$, respectively, in the chromatogram of TPMA0001 recorded at $285 \mathrm{~nm}$ (Figure 2). LC-MS analysis was also performed for the extract to measure the MW of these metabolites [IZI, $m / z \quad 742(\mathrm{M}+\mathrm{H})+$; IZII,

$m / z 758(\mathrm{M}+\mathrm{H})+$ and IZIII, $m / z 774(\mathrm{M}+\mathrm{H})+]$ on LCMS2010 (Shimadzu, Kyoto, Japan) by using reverse-phase HPLC.

To isolate IZII and IZIII, M. rosaria TPMA0001 was cultured in two 300-ml Erlenmeyer flasks, each containing $50 \mathrm{ml}$ of trypticase soy broth. The flasks were incubated on a rotary shaker (120 r.p.m.) at $27^{\circ} \mathrm{C}$ for 3-5 days. Further, $4 \mathrm{ml}$ of the culture was transferred into each of $18500-\mathrm{ml}$ Sakaguchi flasks, each containing $300 \mathrm{ml}$ of trypticase soy broth; these flasks were incubated on a rotary shaker (120 r.p.m.) at $27^{\circ} \mathrm{C}$ for 14 days. The culture filtrate (5l) was passed through a column of HP20 sorbent (Mitsubishi Chemical, Tokyo, Japan). After washing with water, rosamicin derivatives were eluted from the column with $\mathrm{MeOH}$ and the eluate was concentrated to a pasty residue in vacuo. This residue was resuspended in $300 \mathrm{ml}$ of water; the $\mathrm{pH}$ of this suspension was adjusted to 9-11 with $28 \%$ ammonia solution and extracted twice with equal volumes of EtOAc. The organic extracts were combined and concentrated to dryness in vacuo. The crude product was dissolved in chloroform-methanol$28 \%$ ammonia solution (100:10:1), applied to a silica gel column $(28 \times 3 \mathrm{~cm}$, silica gel 60 ; Merck, Darmstadt, Germany), and then eluted using the same mixture. The fractions containing the antibacterial metabolites were applied to a preparative HPLC system [Shim-pack PREP-ODS, internal diameter (i.d.) $=250 \times 20 \mathrm{~mm}$, Shimadzu; mobile phase, acetonitrile- $0.06 \%$ TFA (25:75); flow rate, $20 \mathrm{ml} \mathrm{min}^{-1}$ ]. The $\mathrm{pH}$ of two fractions, which contained IZII or IZIII, was adjusted to 9-11 with $28 \%$ ammonia solution, and these fractions were extracted with an equal volume of EtOAc. After concentrating the organic solution to dryness in vacuo, IZII $(16.6 \mathrm{mg})$ and IZIII $(10.9 \mathrm{mg})$ were obtained.

The molecular formula of IZIII was established as $\mathrm{C}_{39} \mathrm{H}_{67} \mathrm{NO}_{14}$ on the basis of HR-FAB-MS $\left(m / z 796.4465\right.$, calcd for $\mathrm{C}_{39} \mathrm{H}_{67} \mathrm{NO}_{14} \mathrm{Na}, \mathrm{m} / z$ 796.4460). UV $\lambda_{\max }$ of IZIII was at $240 \mathrm{~nm}$ from the UV spectrum data of HPLC analysis. The structure of IZIII was elucidated by NMR spectroscopic studies. Chemical-shift assignments for IZIII were determined on the basis of the DQF-COSY, HMQC, HMBC and NOESY spectral data. The ${ }^{1} \mathrm{H}$ - and ${ }^{13} \mathrm{C}-\mathrm{NMR}$ data of IZIII were compared with those of rosamicin and tylosin, as shown in Table $1 .^{8-10}$ We found that ${ }^{13} \mathrm{C}-\mathrm{NMR}$ spectral data of IZIII were considerably similar to those of rosamicin, except that IZIII did not contain an aldehyde carbon at 202.9 p.p.m. (C-20) or a methyl carbon at 14.5 p.p.m. (C-23) as seen in rosamicin. Instead, IZIII contained an alcohol carbon and an ether carbon at 61.1 and 67.4 p.p.m., respectively. The aldehydic proton H-20 (9.74 p.p.m., s) found in rosamicin was not found in IZIII; instead, a pair of methylene proton $\mathrm{H}-20$ (3.6 and 3.7 p.p.m., m) was observed. The signal detected at 67.4 p.p.m. in IZIII was assigned to C-23, after comparison with the ${ }^{13} \mathrm{C}-\mathrm{NMR}$ data of tylosin. Therefore, IZIII was thought to be a structural derivative of rosamicin; in the former compound, the aldehyde group at C-20 is reduced to alcohol and the methyl group at 
Table $1{ }^{13} \mathrm{C}$ - and ${ }^{1} \mathrm{H}$-NMR data of IZIII, rosamicin and tylosin

\begin{tabular}{|c|c|c|c|c|c|c|c|c|}
\hline \multirow[b]{2}{*}{ Position } & \multicolumn{3}{|c|}{$I Z I I \mid$} & \multicolumn{2}{|c|}{ Rosamicin ${ }^{a}$} & \multicolumn{3}{|c|}{ Tylosin ${ }^{\mathrm{b}}$} \\
\hline & ${ }^{13} \mathrm{C}$ (p.p.m.) & ${ }^{1} H$ (p.p.m.) & $J(H z)$ & ${ }^{13} \mathrm{C}$ (p.p.m.) & ${ }^{1} H$ (p.p.m.) & ${ }^{13} \mathrm{C}$ (p.p.m.) & ${ }^{1} H$ (p.p.m.) & $J(H z)$ \\
\hline 1 & 173.7 & - & - & 173.5 & & 173.9 & - & - \\
\hline \multirow[t]{2}{*}{2} & 39.7 & $2.08(d)$ & 16.5 & 39.7 & $2.1(d)$ & 39.4 & $1.94(\mathrm{dd})$ & $16.5,0.8$ \\
\hline & & $2.57(\mathrm{dd})$ & $16.7,10.6$ & & $2.65(\mathrm{dd})$ & & $2.47(\mathrm{dd})$ & $16.5,10.3$ \\
\hline 3 & 67.4 & $3.85(\mathrm{br} \mathrm{d})$ & 10.8 & 68 & $3.91(\mathrm{br} \mathrm{d})$ & 71.1 & $3.82(\mathrm{br} \mathrm{d})$ & 10.3 \\
\hline 4 & 40.9 & $1.75^{\mathrm{c}}$ & - & 45.1 & & 45.1 & $1.59(\mathrm{dq})$ & $9.1,6.8$ \\
\hline 5 & 81.4 & $3.76(\mathrm{br} \mathrm{d})$ & 9.4 & 81.3 & $3.71(\mathrm{br} \mathrm{d})$ & 81.6 & $3.71(\mathrm{dd})$ & $9.1,1.3$ \\
\hline 6 & 31.9 & $1.65^{c}$ & - & 31.4 & & 32.3 & 2.21 & \\
\hline \multirow[t]{2}{*}{7} & 33.2 & $1.55^{c}$ & - & 31.8 & & 32.9 & 1.48 & \\
\hline & & $1.69^{c}$ & - & & & & 1.52 & \\
\hline 8 & 45.2 & $2.7(\mathrm{~m})$ & - & 37.9 & $2.55(\mathrm{~m})$ & 40.3 & 2.62 & \\
\hline 9 & 201.4 & - & - & 200.9 & & 202.8 & - & - \\
\hline 10 & 123.2 & $6.43(d)$ & 15.8 & 122.8 & $6.46(d)$ & 118.8 & $6.25(d)$ & 15.5 \\
\hline 11 & 150.5 & $6.55(d)$ & 15.8 & 150.9 & $6.53(d)$ & 148 & $7.28(d)$ & 15.5 \\
\hline 12 & 59.4 & - & - & 59.7 & & 143.9 & - & - \\
\hline 13 & 64.4 & 3.17 (d) & 9.8 & 66.8 & $2.82(d)$ & 142.2 & $5.88(d)$ & 10.5 \\
\hline 14 & 43.5 & $1.71^{\mathrm{c}}$ & - & 41.3 & & 44.7 & 2.95 & \\
\hline 15 & 74.0 & $5.3(\mathrm{td})$ & $9.4,2.7$ & 76.8 & $4.89(d)$ & 75.3 & 4.99 (ddd) & $9.4,2.7$ \\
\hline \multirow[t]{2}{*}{16} & 24.8 & $1.55(\mathrm{~m})$ & - & 24.7 & & 25.5 & 1.56 & \\
\hline & & $1.89(\mathrm{~m})$ & - & & & & 1.89 & \\
\hline 17 & 9.2 & $0.89(\mathrm{td})$ & 7.4 & 9.1 & & 9 & $0.94(\mathrm{t})$ & 7.3 \\
\hline 18 & 9.2 & $1.13(\mathrm{~d})$ & 6.8 & 9 & & 9.6 & 0.99 (d) & 6.8 \\
\hline \multirow[t]{2}{*}{19} & 31.9 & $1.96(\mathrm{~m})$ & - & 43.8 & $2.46(\mathrm{~m})$ & 43.9 & 2.36 & \\
\hline & & & & & $3.08(\mathrm{~m})$ & & 2.86 & \\
\hline \multirow[t]{2}{*}{20} & 61.1 & $3.66(\mathrm{~m})$ & - & 202.9 & 9.73 (s) & 203 & $9.68(d d)$ & $1.9,1.0$ \\
\hline & & $3.7(\mathrm{~m})$ & - & & & & & \\
\hline 21 & 17.4 & $1.51(\mathrm{~d})$ & 6.8 & 17.4 & & 17.4 & $1.21(\mathrm{~d})$ & 6.8 \\
\hline 22 & 14.9 & $1.42(\mathrm{~s})$ & - & 15 & & 13 & $1.79(\mathrm{~d})$ & 1.2 \\
\hline \multirow[t]{2}{*}{23} & 67.4 & $3.64(d d)$ & $10.6,2.7$ & 14.5 & & 68.2 & $3.56(d d)$ & $9.7,6.2$ \\
\hline & & $4.14(d d)$ & $10.1,3.2$ & & & & $3.96(d d)$ & $9.7,4.2$ \\
\hline $1^{\prime}$ & 104.8 & 4.31 (d) & 7.3 & 104.5 & $4.22(d)$ & - & & \\
\hline $2^{\prime}$ & 70.4 & $3.23(\mathrm{dd})$ & 10.0, 7.3 & 70.4 & $3.2(\mathrm{dd})$ & - & & \\
\hline $3^{\prime}$ & 65.8 & $2.53(\mathrm{brt})$ & 10.7 & 65.8 & $2.49(\mathrm{~m})$ & - & & \\
\hline \multirow[t]{2}{*}{$4^{\prime}$} & 28.6 & $1.26^{c}$ & - & 28.4 & & - & & \\
\hline & & $1.68^{c}$ & - & & & & & \\
\hline $5^{\prime}$ & 69.6 & $3.5(\mathrm{~m})$ & - & 67.7 & $3.46(\mathrm{~m})$ & - & & \\
\hline $6^{\prime}$ & 21.1 & $1.22(\mathrm{~d})$ & 6.1 & 21.2 & & - & & \\
\hline $7^{\prime}$ & 40.3 & $2.32(\mathrm{~s})$ & - & 40.5 & $2.29(\mathrm{~s})$ & - & & \\
\hline $8^{\prime}$ & 40.3 & $2.32(\mathrm{~s})$ & - & 40.5 & $2.29(\mathrm{~s})$ & - & & \\
\hline $1^{\prime \prime}$ & 100.9 & $4.56(d)$ & 7.7 & - & & 101.1 & $4.56(d)$ & 7.8 \\
\hline $2^{\prime \prime}$ & 82.0 & $3.09(\mathrm{dd})$ & $7.6,2.9$ & - & & 82 & $3.01(\mathrm{dd})$ & $7.8,3.0$ \\
\hline $3^{\prime \prime}$ & 79.7 & $3.77(t)$ & 3 & - & & 79.9 & $3.74(t)$ & 3 \\
\hline $4^{\prime \prime}$ & 72.7 & $3.21(\mathrm{dd})$ & $9.4,3.2$ & - & & 72.9 & $3.15(44)$ & $9.4,3.0$ \\
\hline $5^{\prime \prime}$ & 70.8 & $3.52(\mathrm{~m})$ & - & - & & 70.6 & 3.53 & \\
\hline $6^{\prime \prime}$ & 17.8 & $1.26(\mathrm{~d})$ & 6 & - & & 17.8 & $1.25(\mathrm{~d})$ & 6.2 \\
\hline $7^{\prime \prime}$ & 59.7 & $3.56(\mathrm{~s})$ & - & - & & 59.6 & $3.48(\mathrm{~s})$ & \\
\hline $8^{\prime \prime}$ & 61.7 & 3.62 (s) & - & - & & 61.7 & $3.60(\mathrm{~s})$ & \\
\hline
\end{tabular}

aData from Nakajima et al. ${ }^{8}$

bata from Ōmura et al. ${ }^{9}$ and Simova and Inanova. ${ }^{10}$

${ }^{\mathrm{c} O v e r l a p p i n g .}$

C-23 is modified. Tylosin has a mycinose moiety at C-23, and the ${ }^{1} \mathrm{H}$ - and ${ }^{13} \mathrm{C}-\mathrm{NMR}$ data of IZIII coincided well with those of this mycinose moiety. On the basis of these results, the structure of IZIII was determined as 23-O-mycinosyl-20-dihydro-rosamicin.

UV $\lambda_{\max }$ of IZII $[\mathrm{m} / z 758(\mathrm{M}+\mathrm{H})+]$ were at $287 \mathrm{~nm}$ from UV spectrum data of HPLC analysis. To estimate the structure of IZII, the ${ }^{1} \mathrm{H}$ - and ${ }^{13} \mathrm{C}-\mathrm{NMR}$ data of IZII was compared with those of IZIII
(Supplementary Table S1). The ${ }^{1} \mathrm{H}$ - and ${ }^{13} \mathrm{C}$-NMR spectra of IZII resembled those of IZIII except for the proton and carbon signals of C-12 and C-13. The chemical shifts of C-12 and C-13 of IZII were 135.0 and 141.8 p.p.m., respectively, and indicated the alkene carbons. Also, the chemical shifts of H-13 of IZII and IZIII were 5.88 p.p.m. (d) and 3.17 p.p.m. (d), respectively, and H-13 in IZII was an alkene proton. On the basis of these results, the structure of IZII was 
Table 2 Antibacterial activity of rosamicin, IZI, IZII and IZIII

\begin{tabular}{lccr}
\hline & & \multicolumn{2}{c}{ MIC $\left(\mu g \mathrm{ml}^{-1}\right)$} \\
\cline { 2 - 4 } Microorganism & Rosamicin & IZI & IZIII \\
\hline S. aureus ATCC 25923 & 0.20 & 0.20 & 0.39 \\
M. luteus ATCC 9341 & 0.048 & 0.048 & 0.097 \\
S. enterica serovar Typhimurium ATCC 14028 & 6.25 & 100 & $>1.56$ \\
E. coli ATCC 25922 & 3.12 & 50.0 & $>0.20$ \\
\hline
\end{tabular}

estimated as 23-O-mycinosyl-20-dihydro-12,13-deepoxyrosamicin, and the compound has been already reported as a bioconversion compound, which was converted from 20-deoxo-20-dihydro-12,13deepoxy-12,13-dihydrorosaranolide by the mycinamicin non-producing mutant GS-9001. ${ }^{11}$

The antibacterial activity of IZII and IZIII, which was tested on Staphylococcus aureus ATCC 25923, Micrococcus luteus ATCC 9341, Salmonella enterica serovar Typhimurium ATCC 14028, and E. coli ATCC 25922, was lower than that of rosamicin and IZI (Table 2). The antibacterial activity of IZI against gram-positive bacteria ( $S$. aureus ATCC 25923 and M. luteus ATCC 9341) was very similar to that of rosamicin; however, the activity of IZII and IZIII was lower than that of rosamicin and IZI.

Two types of cytochrome P450 enzymes are considered to be responsible for $\mathrm{C}-20$ oxidation and $\mathrm{C}-12 / 13$ epoxidation in the rosamicin biosynthetic pathway of $M$. rosaria IFO13697. ${ }^{4}$ The rosamicin biosynthetic pathway was elucidated with reference to the tylosin biosynthetic pathway because the structure of rosamicin is very similar to that of $O$-mycaminosyltylonolide, an intermediate in the tylosin biosynthetic pathway. ${ }^{12,13}$ In the tylosin biosynthetic pathway, the cytochrome P450 protein TylI has been proposed to convert 5-mycaminosyl-tylactone to 23-deoxy-O-mycaminosyl-tylonolide through 20-dihydro-23-deoxy-O-mycaminosyl-tylonolide; that is, TylI is believed to catalyze both hydroxylation and dehydrogenation at C-20 of 5-mycaminosyl-tylactone. Moreover, the TylI protein has been thought to catalyze hydroxylation and dehydrogenation at the C-20 position of 5-mycaminosyl tylacone. ${ }^{13,14}$ Therefore, the hydroxyl group at the C-20 position in IZII and IZIII was probably generated by the action of the cytochrome P450 enzyme, which is responsible for C-20 formylation in rosamicin; further, this could be attributed to the conserved biosynthetic pathway of rosamicin in $M$. rosaria TPMA0001. Moreover, the epoxy group at C-12/13 in IZIII was probably generated by the action of another cytochrome $\mathrm{P} 450$ enzyme, which is responsible for $\mathrm{C}-12 / 13$ epoxidation in rosamicin. However, a mycinosyl rosamicin derivative with formylated C-20 has not yet been detected in the culture broth of M. rosaria TPMA0001.

1 Rodriguez, E. \& McDaniel, R. Combinatorial biosynthesis of antimicrobials and other natural products. Curr. Opin. Microbiol. 4, 526-534 (2001).

2 Salas, J. A. \& Mendez, C. Engineering the glycosylation of natural products in actinomycetes. Trends Microbiol. 15, 219-232 (2007).

3 Wagman, G. H. et al. New Micromonospora-produced macrolide antibiotic, rosamicin. J. Antibiot. 25, 641-652 (1972).

4 Anzai, Y. et al. Production of rosamicin derivatives in Micromonospora rosaria by introduction of D-mycinose biosynthetic gene with $\phi$ C31-derived integration vector pSET152. J. Ind. Microbiol. Biotechnol. 36, 1013-1021 (2009).

5 Anzai, Y. et al. Organization of the biosynthetic gene cluster for the polyketide macrolide mycinamicin in Micromonospora griseorubida. FEMS Microbiol. Lett. 218, 135-141 (2003).

6 Anzai, Y. et al. Functional analysis of $\mathrm{MycCl}$ and $\mathrm{MycG}$, cytochrome P450 enzymes involved in biosynthesis of mycinamicin macrolide antibiotics. Chem. Biol. 15, 950-959 (2008)

7 Li, S., Anzai, Y., Kinoshita, K., Kato, F. \& Sherman, D. H. Functional analysis of MycE and $\mathrm{MycF}$, two $\mathrm{O}$-methyltransferases involved in biosynthesis of mycinamicin macrolide antibiotics. Chem. Biol. Chem. 10, 1297-1301 (2009).

8 Nakajima, S., Kojiri, K., Morishima, H. \& Okanishi, M. New analogs of rosaramicin isolated from a Micromonospora strain. II. Structure determination. J. Antibiot. 43, 1006-1009 (1990).

9 Ōmura, S. et al. Carbon-13 nuclear magnetic resonance spectral analysis of 16-membered macrolide antibiotics. J. Am. Chem. Soc. 97, 4001-4009 (1975).

10 Simova, S. \& Ivanova, G. Proton and carbon chemical shift assignment and solutionstate conformation of macrocyclic ring in macrolide antibiotic tylosin in aprotic solvents. Magn. Reson. Chem. 34, 255-260 (1966).

11 Lee, B. K. et al. Multistep bioconversion of 20-deoxo-20-dihydro-12,13-deepoxy12,13-dehydrorosaranolide to 22-hydroxy-23-0-mycinosyl-20-deoxo-20-dihydro12,13-deepoxyrosaramicin. J. Antibiot. 36, 742-744 (1983).

12 Baltz, R. H. \& Seno, E. T. Properties of Streptomyces fradiae mutants blocked in biosynthesis of the macrolide antibiotic tylosin. Antimicrob. Agents Chemother. 20, 214-225 (1981).

13 Baltz, R. H., Seno, E. T., Stonesifer, J. \& Wild, G. M. Biosynthesis of the macrolide antibiotic tylosin a preferred pathway from tylactone to tylosin. J. Antibiot. 36, 131-141 (1972).

14 Merson-Davies, L. A. \& Cundliffe, E. Analysis of five tylosin biosynthetic genes from the tyllBA region of the Streptomyces fradiae genome. Mol. Microbiol. 13, 349-355 (1994).

Supplementary Information accompanies the paper on The Journal of Antibiotics website (http://www.nature.com/ja) 